\title{
Exploring the Co-Teaching Experience in a Graduate-Level, Principal Preparation Course
}

\author{
Jafeth E. Sanchez, PhD \\ Assistant Professor, Department of Educational Leadership \\ University of Nevada, Reno \\ Kelly Humphreys, $\mathrm{PhD}$ \\ Principal, Rita Cannan Elementary School \\ Washoe County School District \\ Kevin Carroll, MEd \\ Principal, Sparks High School \\ Washoe County School District
}

This article presents a case study conducted by three co-instructors (one faculty member and two practicing principals) who examined their experiences co-teaching a newly revised, graduate-level, principal preparation course. Three themes were identified through their experiential stories: strengths of the co-teaching model, supports and needs, and hindrances.

These primary themes, along with notable subthemes are detailed. A discussion on coteaching as an innovative teaching method in higher education is provided with a particular focus at the graduate level. Implications for practice and suggestions for future research are discussed in light of these unique findings on co-teaching experiences.

The role of the principal matters and remains a key variable in influencing student learning and school success (Branch, Hanushek, \& Rivkin, 2013; Syed, 2015; Thomas \& Kearny, 2010). More specifically, high-quality school leaders are able to develop strong school cultures that support student learning and encourage teacher retention (Loewenberg, 2016). Researchers have documented, however, that principal vacancies are expected to climb, and the difficulty of filling existing school leadership openings will continue to be a challenge moving forward (Ash, Hodge, \& Connell, 2013; Gurley, Anast-May, \& Lee, 2015; Russell \& Sabina, 2014; Stone-Johnson, 2014). This concern is exacerbated under the understanding that even successful identification and recruitment of aspiring leaders "is not sufficient to ensure a highly qualified principal in every school" (Thomas \& Kearny, 2010, p. 9). Certainly, the position of school leader requires more than a warm body or an individual who meets licensure qualifications; principals should be hired "with the capacity to lead students to higher achievement levels" (Ash et al., 2013, p. 95). In other words, aspiring school leaders must be effectively prepared and ready to serve as high-quality school leaders.

The need to adequately prepare future school leaders is evident. As a result, there is also a critical need to re-conceptualize teaching and learning for graduate-level coursework in principal preparation programs, and the scholarship of teaching and learning can support this necessity. For example, Draeger (2013) states, "the scholarship of teaching and learning offers the prospect of helping students learn more effectively and provides professors opportunities for intellectual growth" (p. 16). Undoubtedly, professors of principal preparation courses can look to such scholarship to redesign courses to meet student needs. Therefore, the purpose of this case study is 
The need to adequately prepare future school leaders is evident. As a result, there is also a critical need to re-conceptualize teaching and learning for graduate-level coursework in principal preparation programs, and the scholarship of teaching and learning can support this necessity. to explore one co-teaching experience in a research university in the Western United States in an introductory graduate-level, principal preparation course. The course was revised in an effort to enhance the coursework experience and optimally prepare aspiring principals to serve as highly

effective school leaders. The researchers, all co-instructors (one faculty member and two practicing principals), engaged in reflective writing and analysis to focus on the strengths, supports, and possible hindrances to the co-teaching experience as perceived by each co-instructor. The results offer insightful areas to consider in the scholarship of teaching and learning in this discipline, provide the co-teaching model as an innovative strategy to improve principal preparation programs, and contribute to a gap in the literature of co-teaching in higher education.

\section{Relevant Literature Review}

Three areas of literature support the work of this study. The first is rooted in the need to develop high-quality school principals and, in turn, the demands to improve principal preparation programs. The second portion of relevant literature relates to the efforts, key features, or components that tend to represent improvements for principal preparation programs. The last portion of our literature review narrows in on what could serve as a key feature of principal preparation programs but has been lacking among program improvement efforts. Specifically, relevant literature related to co-teaching is presented, particularly with notable outcomes in higher education.

\section{Principal Preparation Programs}

The adequate preparation of graduates from principal preparation programs is largely debated in the United States (Dodson, 2015). The need for high-quality principals, along with the criticisms of college and university principal preparation, have created demands for the redesign of educational leadership programs. For example, nearly two decades ago, the Southern Regional Education Board (SREB, 2002) highlighted universities in the lead for redesigning leadership preparation programs. The SREB (2002) reported institutional efforts that included university-district collaboration and a departure from the traditional model; they shared an increased focus on specific strategies, such as the inclusion of challenging problem-solving assignments, mentoring, and extensive, integrated field experiences. Efforts to enhance preparation programs are vast and commonly maintain a clear focus on intentional, real, hands-on experiences. Some of this work was captured since 2005 in the work of Fry, Bottoms, and O'Neill and more recently by the New York City Leadership Academy (2015). Interestingly, Dodson's (2015) study of seven states did not find a "clear cut relationship between requiring field experiences or internships and the overall education quality in the states studied" (p. 14). Still, meaningful internship experiences seem to be a consistent feature among program improvements 
and have been identified as a critical component to the principal preparation process (Davis, 2016).

\section{Program Improvements}

Improvements for effective or innovative principal preparation programs include a coherent program of study, embedded field experiences, cohort-selection models, connections between theory and practice, strong district-university partnerships, and effective principals serving as mentors or coaches (Campanotta, Simpson, \& Newton, 2016; Davis \& Darling-Hammond, 2012). These improvements are essential because the course of study in particular is often not reflective of the principal's job (Davis, 2016). The coursework should reflect what principals need to know under the guidance of faculty members who encompass research expertise and practitioner experiences. Indeed, Campanotta et al.'s (2016) findings on elite leadership preparation programs affirmed that principals are better prepared for their roles when coursework integrates field experiences with research, theory, and practice. Understandably, a logical solution is to attract faculty members who reflect this type of course integration, but there are clear limitations in attracting faculty members who are researchers and have recent practitioner experiences (Davis, 2016). Perhaps an alternative method to reconcile the existing need for the researcher and practitioner lenses, in addition to the shortcomings of faculty members to fill this role, is to consider the use of a co-teaching model in graduate-level, principal preparation courses. Unfortunately, "the extent of co-teaching at the university level has been much less prevalent and very loosely studied" (Bacharach, Heck, \& Dahlberg, 2008, p. 9).

\section{Co-Teaching in Higher Education}

A thorough literature review revealed that the scholarship of teaching and learning using a co-teaching model in principal preparation programs is visibly lacking. To illustrate, a literature review using the Academic Search Complete database, limited to peer-reviewed journals, and using the search terms, higher education and co-teaching or team teaching or collaborative teaching or cooperative teaching, listed only 248 articles within the last decade. A similar search using terms, co-teaching and education yielded only 140 articles within the last decade, and most articles focused on areas of pre-service teaching or inclusive settings for students with disabilities in K12 or undergraduate education. Altogether, none of the articles focused on the graduate level nor within principal preparation programs.

Researchers recognize that co-teaching has predominantly been part of the K12 educational setting and has only more recently reached higher education institutions (Ferguson \& Wilson, 2011; Lusk, Sayman, Solkoski, Carrero, \& Chui, 2016; Morelock et al., 2017). Lusk et al. (2017) found that co-teaching in higher education can "promote effective teaching for teacher educators and their teacher candidates" (p. 52). Outside the field of education, in a designs foundation course, Tillman, Arnold, and Barnett (2010) also found multiple benefits to co-teaching, such as highly effective management of the course, content, and workloads, while still enhancing student experiences. Although the aforementioned findings were at the undergraduate level, 
similar benefits could occur within principal preparation programs for co-instructors and their aspiring principal candidates at the graduate level.

According to Cook and Friend (1995), co-teaching represents "two or more professionals delivering substantive instruction to a diverse, or blended, group of students in a physical space" (p. 2). Even though their work focused on the K12 setting and with a special education lens, the authors affirmed that co-teaching provides differing but complementary perspectives among the professionals who co-teach and increases instructional options for all students. At the higher education level, Bacharach, Heck, and Dahlberg (2008) similarly concluded that co-teaching "allows the blending of university theory and classroom practice" when different individuals can bring those perspectives into the coursework (p. 13). Bacharach et al. (2008) included planning, organization, delivery and assessment, and the physical space as part of the co-teaching model in higher education.

Furthermore, Bacharach et al. (2008) found multiple benefits for students and the co-instructors. For example, students reported instructional benefits, such as a lower student-to-teacher ratio, exposure to various perspectives, and enhanced use of instructional time; faculty appreciated the sharing in planning and teaching, reflection, and the ability to learn additional teaching and learning strategies. There were some shortcomings found by Bacharach et al., as reported by students; these included some confusion about grading, whom to seek when needing help, and some concerns with inequitable distribution of instructional time among those co-teaching. Each of these concerns were alleviated, however, through increased communication, such as overt statements related to course policies, practices, and grading (Bacharach et al., 2008).

\section{Method}

A qualitative methodological approach was used to examine co-instructor (one faculty member and two principals) reflections of their first time co-teaching a graduate-level, principal preparation introductory course on educational leadership, EL 700. The authors for this study (all co-instructors) were interested in exploring their co-teaching experiences through open-ended questioning to better understand the possible strengths and drawbacks with co-teaching in this unique setting. Considering the focus and inquiry, the use of qualitative research to explore and understand the meaning that others ascribe to a social or human issue is supported by Creswell (2014). Also within qualitative research, a case study is defined as "a single entity around which are boundaries (Merriam, 1998, p. 27). Therefore, EL 700, served as the bounded phenomena for this case study.

\section{The Co-Teaching Approach}

As a unique component within the complete redesign of a principal preparation program, the co-teaching model was implemented in the graduate-level course, EL 700, at a research university in the Western United States. The course highlights leadership styles, approaches, and theories, and exposes students to the Professional Standards for Educational Leadership (National Policy Board for Educational Administration, 2015). The course was revised as part of the universitydistrict partnership to redesign the program; from that partnership, two of the principals involved in the revision volunteered to co-teach the course with the lead 
faculty member. The redesign team opted to include both principals because one focuses on the secondary level and the other focuses on the primary level. The aim was that their perspectives, along with the faculty member's lens, would further enhance the aspiring school leaders' experiences in the course.

The principal preparation course was co-taught by all three co-instructors during Spring 2017 to a cohort of 25 aspiring school leaders who were admitted to the program that semester. The course was taught once weekly, and the principals alternated teaching weeks, so that only two individuals (one faculty member and one principal) were in the physical space at once. However, all three instructors were in the course together during the first and last meetings of the semester. Specific weekly planning to revisit prior group decisions occurred throughout the week, but the principals and faculty member met every week, one hour before class to solidify the week's lesson plan, reflect, and consider necessary refinements to the course.

Importantly, from a budgetary standpoint, this commitment to the program and course redesign required an additional cost to have the instructors hired on a Letter of Appointment (LOA) contract. As an LOA, the cost at this institution's college of education is approximately $\$ 1,000$ per credit. Therefore, the approximate cost for a 3credit course is $\$ 3,000$ per semester, but because the co-instructors were alternating weeks, then that total cost was split between both instructors.

\section{Research Questions}

During Spring 2018, all three co-instructors met in person and communicated via email to identify a structure for the study. This meeting was intentionally arranged after the conclusion of the first co-teaching experience but prior to co-teaching the course for a second time so that each co-instructor could reflectively and specifically focus only on the first teaching experience. The faculty member (lead author) facilitated all processes of the study's design but sought input from both principals (coauthors). The first meeting focused on the study's outline and potential research questions. Then, email communication was used to determine, review, and revise open-ended questions to reflect upon the co-teaching experience.

The first four open-ended questions were framed using the work by Davis (2016) and Campanotta et al. (2016) to better understand each co-instructor's practical lens, experiences, and personal motivations that might lend themselves to bridging principal preparation improvements with a co-teaching model. The next four openended questions were based on co-teaching research (Bacharach et al. 2008; Cook \& Friend, 2008; Tillman et al., 2010) to specifically examine and hone in on possible benefits and shortcomings within the higher education setting. The questions that were identified were: (a) Describe your leadership background, (b) Why did you want to work to redesign a master's course? (c) What were your hesitations to teaching? (d) What did you see as your strengths to teaching? (e) What supports the process of coteaching, from your perspective? (f) What hinders (or could hinder) the process of coteaching, from your perspective? (g) What practical implications does a co-teaching model offer? (h) What would someone in this position need to know to be successful?

\section{Data Collection and Analysis}

Once these questions were finalized, the faculty member and the two principals agreed to provide written responses to these questions, in narrative form, to 
serve as data for the case study. The faculty member and principals agreed to independently write the responses and not read/review others' responses until all authors' writing was complete. The authors believed this would strengthen the study and could help to reduce bias, as reading co-instructors' responses could inherently shape one's responses.

After all writing was complete, the faculty member asked the principals to consider each set of responses (narratives) as separate data sources. The authors then independently read their own responses and looked for themes, read others' responses and looked for themes, and finally explored all three narratives together to consider central themes. This process was used as a form of triangulation (Creswell, 2014; Stake, 2010). After this analysis occurred independently, the three authors met to discuss themes and agree upon the findings of this case study.

Of note, Creswell's (2014) validity strategies (i.e., triangulation, member checking, articulation of bias) were integrated, but the authors understand that individual identity, experiences, and characteristics can still impact findings and interpretations. Despite efforts to be objective in the process, biases can have some influence on a case study (Treacy, Casillas, \& Wiest, 2013). For example, all coinstructors initially agreed to co-teach because they believed it was an important opportunity to enhance the preparation of aspiring school leaders. This belief could inherently influence responses related to the experience. In addition, each author understood that responses from the lead author, who is a university faculty member, could be inherently different than the responses from co-authors, who are primarily external to the university as current school principals.

\section{Findings}

Three themes were identified in this study. The participants' narratives focused on strengths of the co-teaching model, supports and needs for effective coteaching, and potential hindrances to successful co-teaching. Notably, most of the written evidence within these themes centered on the strengths of co-teaching, as well as on the supports and needs essential to its effectiveness. As a result, subthemes were found within strengths of co-teaching, as well as within the supports and needs for effective co-teaching. The narratives also exposed similarities related to potential hindrances, but this theme was not as pronounced as the others. Also, even though a formal analysis of student learning outcomes was not conducted for this study, students' general responses are shared within the findings, given the importance of student learning outcomes within the context of the scholarship on teaching and learning.

\section{Strengths of the Co-Teaching Model}

Participant narratives focused on various strengths within the co-teaching experience. The strengths were identified by the data as three subthemes. The most salient subtheme was focused on the blending of theory to practice within the course; the next subtheme was uniquely centered on course relevancy for students, and the 
third subtheme was focused on the co-instructors' personal experiences that served to enhance the co-teaching experience.

Blending of theory to practice. The course revision stemmed from a need to develop high-quality school principals. The lead faculty member (lead author) not only recognized this need but also recognized her personal shortcomings as a practitioner that could be reconciled through the co-teaching model. In her narrative, Jafeth wrote, "I was lacking personal experience of having been a school principal. I understood the school principal role through my research...but I imagined that the person (or people) co-teaching with me could be fantastic to work with and really make an impact at multiple levels." Kelly stated, "I feel that it bridges theory and practice in offering both conceptual and applied experiences." Kelly explained that co-teaching provided the "ability to bring expertise from theory and practice to graduate level students...[original ellipse] the melding of perspectives, and honest and deeper conversations about possible disconnects between concepts and one's ability to apply them." Similarly, Kevin noted that the blending of theory to practice strengthens the co-teaching experience as "this type of model gives students many different perspectives on leadership theory and application." Thus, all participants seemed to recognize a blending of theoretical and practical perspectives through their co-teaching experience.

Course relevancy. Connected to the theory to practice perspective in the course, all participants stressed that a strength to the co-teaching model and experience was the course relevancy for students in the graduate-level, principal preparation course. Kelly affirmed, "the level of preparedness of educational leaders varies widely and this partnership to redesign a program has the potential to offer an exceptional experience in training and preparing leaders." She added that co-teaching provides "very specific applied examples of 'leadership in practice' that has contextual relevance for many students who are part of the public school system, while pursuing their MA degree." This view was also evidenced in Kevin's narrative; he indicated that his leadership knowledge can uniquely engage students in discussions that helps them "to understand what leadership is and what it entails at different levels." While Jafeth addressed the importance of continuing to include a research- and theory-based perspective, along with essential course activities through co-teaching, she also noted, "but an extension to that is that they [students] can then actually ask a principal more in-depth aspects about the topics at hand."

Personal experience. Personal experience can likely be tied to the course relevancy that was brought to the co-teaching experience in EL 700. All co-instructors referenced their personal experience or background in their narratives and identified contributions to the co-teaching model. For example, in Jafeth's narrative, she detailed that leadership experiences had been a part of most of her life in multiple ways. Jafeth stated, "As far back as I can remember, I have been in 'positions' of leadership." She described how early experiences in leadership and even recent experiences in becoming a mother have all strengthened her leadership lens. The author wrote, "I am comfortable serving as a master juggler and wearing many hats." The third author similarly referenced his personal experiences and indicated having been in education for over 26 years. Nevertheless, perhaps Kelly's statement serves as the most 
compelling evidence of personal experience as a strength to co-teaching. The author reflected:

Serving in diverse leadership roles over time has informed my practice and thinking around leadership. I have been an educational leader for 13 years in roles that include Lead Psychologist/Coordinator of Psychological Services, central office administrator offering support/supervision to schools, and elementary principal. These opportunities have all contributed to my growth and development as a leader...[original ellipse] and, ignited my desire to help grow future leaders.

Thus, co-instructors seemed to recognize personal leadership experience and their respective contributions to the co-teaching experiences in the course.

\section{Supports and Needs}

While the co-instructors' experiential stories revealed specific strengths of the co-teaching experience, they also referenced the types of supports that were essential or addressed specific needs that could foster a successful co-teaching experience in a graduate-level, principal preparation program. Two subthemes - positive relationships and open communication - were identified as the dominant findings related to supports and needs.

Positive relationships. Positive relationships seemed to be a necessary part of the co-teaching experience, as shared by the co-instructors. Words such as "flexible," "trusting," "understanding," "respect," "willingness," and "honest" were used by the co-instructors throughout their narrative responses. All co-instructors referenced positive co-instructor relationships as opportunities to learn together while also focusing on the best interest of students. Jafeth recalled being strangers when they first began the course revision for the program redesign and declared, "We are now colleagues and, even better, we are friends."

Open communication. Communication as a key support of the co-teaching experience was a prominent part of the co-instructors' narratives. For example, Kevin expressed that communication was essential to supporting the processes. He explained, "Being able to communicate and having an open mind allows us to complement each other's strengths that, in turn, benefits our students." The second author similarly noted that open communication reflected a willingness to welcome others' contributions, while "respecting the different strengths that each co-teacher brings to the course." In addition, Jafeth stated, "I thought that my calm, but outgoing, personality could help forge strong relationships to be open and transparent in the coteaching experience." She added that they also needed open communication in order to "calibrate" on the expectations and grading processes, while celebrating moments that helped maintain a strong momentum for the co-teaching experience.

\section{Hindrances}

The co-instructors commonly reported potential hindrances to co-teaching. For example, Jafeth shared, "I was concerned about that extra time negatively impacting my focus on research, particularly at a research university," but wrote that 
the effort could be transformational for the program and course, so she committed to it. Also related to time concerns, Kelly shared worries around "balancing my demands of my role as principal, family commitments, and life." The third author similarly pointed to the time commitment to co-teaching but indicated that it was not an issue in his own co-teaching experience for this course. Kevin affirmed, "I know if there is a lack of communication co-teaching will fail." In addition, "not being willing to relinquish 'control' or embrace equitable roles in facilitating the class - feeling differing degrees of ownership," was expressed by Kelly. Ultimately, the co-instructors referred to their stated supports or needs (i.e., characteristics of positive relationships, open communication) and indicated that a lack of these aspects could hinder the co-teaching experience.

\section{Students' Responses}

While a formal analysis of student learning outcomes was not conducted for this study, students' general responses are highlighted to augment the focus on the scholarship of teaching and learning. First, the majority of students in the course already held a master's degree, but they indicated having pursued this course as part of their second master's degree specifically because of the co-teaching model and the opportunity to gain a theory-to-practice perspective with each course session. Students communicated that they believed this would make them a stronger candidate for a school leadership role. Second, throughout the semester, many students commented that the class could benefit from an extra 30 minutes to allow even more time for discussion and questions. This finding affirmed that students identified course activities as being relevant and meaningful. Third, after some classes, students actually clapped at the conclusion of the course to praise the session activities and experience; indeed, each co-instructor noted that it was the first time having experienced this type of positive feedback after a course session.

Along with general feedback from students indicating that they were valuing their learning experiences, the co-teaching model also seemed to foster the opportunity for students and co-instructors to build a strong rapport. For example, as the semester was nearing its end, students suggested meeting after the last course session for a happy hour event to thank the co-instructors and connect outside of the course. Furthermore, to the co-instructors' surprise, on the final course day, students gave each co-instructor a personalized thank you card that had been signed by every student. In the card, students referenced various learning experiences that they valued from the course and its co-instructors. In addition, a general review of the university's student evaluations indicated that the students' mean ratings were higher for EL 700 as compared to the college and university mean ratings during the Spring 2017 semester. Finally, all 25 students persisted in the program and graduated in the fall of 2018.

\section{Discussion}

The themes in this case study for the EL 700 co-teaching experience at the graduate level, in combination with the increased need to improve principal preparation programs and the limited scholarship in teaching and learning, support 
the possible expansion of co-teaching in this discipline. Moreover, the themes reveal that co-teaching at the graduate level can reflect positive experiences for those involved, but there are specific aspects that must be undertaken in that process to make it successful. Indeed, Tsai and Wang (2017) indicated that this is a different teaching approach with pros and cons to the model. In Dickey, Kline, and Lindsteadt's (2016) work, the researchers posited that establishing new models of instruction could help graduates remain competitive elsewhere.

Perhaps, most importantly, it appears that each finding in this study reflects the co-instructors' deep commitment to co-teaching in order to improve aspiring school leader outcomes. Draeger (2013) asserted that "the scholarship of teaching and learning matters because learning matters" (p. 17), so if educational leaders are indeed invested in preparing high-quality school leaders, further scholarship must occur that documents innovative efforts in this regard. Recently, Henley and Cook (2018) called for a re-envisioning of the university, including the funding of co-teaching partnerships and respective support for this research and teaching. Those with the ability to transform the scholarship in teaching and learning in any field of study should not shy away from opportunities to explore co-teaching in higher education, especially at the graduate level. Perhaps equally urgent, to enhance principal preparation programs and their candidates, the co-teaching model could serve as a key feature within this unique discipline.

\section{Implications for Practice}

There are several implications for practice, especially for those interested in implementing a co-teaching model for graduate-level coursework in principal preparation programs. For example, the budgetary implications of multiple instructors in a course must be accepted. The cost to support a co-teaching model will certainly vary by institution, college, and discipline. Therefore, it requires a clear commitment from all stakeholders involved. Certainly, grants exist as a viable option to enhance students' meaningful learning experiences, but sustainability of such a model should be strongly supported by existing funding, if possible. Also, university-district partnerships remain critical to principal preparation program improvement. In this study, that partnership served to establish this co-teaching model. In that same regard, individuals who partake in a course redesign to implement a co-teaching model should be encouraged to share their concerns or hesitations for the process, such as those shared by the co-instructors in this case study. Doing so can allow courageous

Those with the ability to transform the scholarship in teaching and learning in any field of study should not shy away from opportunities to explore co-teaching in higher education, especially at the graduate level. conversations to occur while helping to ease the process of co-teaching. More generally, at the onset of any co-teaching experience, co-teaching (or group) norms should be established to help nurture the process, including the strengths, as well as the supports and needs, identified in this study. The establishment of these norms could also help reduce potential hindrances (time concerns, balancing of roles, etc.) to support successful co-teaching experiences. Those involved in the process should be ready to be flexible, while also being willing to contribute ideas and experiences. 
Efforts to ensure that co-teaching brings diverse perspectives should be embraced in order to include theoretical and practical perspectives that can enhance the course experience and bring light to the needs of the ever-changing principal role.

\section{Recommendations for Future Research}

The findings of this case study identified themes that supported successful coteaching experience. Research related to poor, challenging, or unsuccessful experiences would help to illuminate more areas to explore and consider in the coteaching experience. Also, the students' experiences in EL 700 were not formally captured in this study; it would be beneficial to include the student voice in future studies, along with their course evaluations and course outcomes as a direct analysis of student learning. Furthermore, while this captured one first-time experience in coteaching, it would be valuable to consider similar cases using longitudinal case studies to determine how these findings change or shift over time. Finally, replication of the current study, but in other classes and with other co-instructors within the same discipline, should be conducted to contribute to this literature and provide a better understanding of the co-teaching model at the graduate level.

\section{References}

Ash, R. C., Hodge, P. H., \& Connell, P. H. (2013). The recruitment and selection of principals who increase student learning. Education, 134, 94-100.

Bacharach, N. Heck, T. W., \& Dahlberg, K. (2008). Co-teaching in higher education. Journal of College Teaching and Learning, 5, 9-16.

Branch, G., Hanushek, E., \& Rivkin, S. (2013). School leaders matter: Measuring the impact of effective principals. Education Next, 13, 62-69.

Campanotta, L., Simpson, P., \& Newton, J. (2016). Program quality in leadership preparation programs: An assessment tool. Paper presented at the summer conference of the National Council of Professors of Educational Administration, Detroit, MI. Retrieved from

http://www.ncpeaprofessor.org/2016-

detroit-conference.html
Cook, L., \& Friend, M. (1995). Coteaching: Guidelines for creating effective practices. Focus on Exceptional Children, 28, 1-16.

Creswell, J. W. (2014). Research design: Qualitative, quantitative, and mixed methods approaches. Thousand Oaks, CA: Sage.

Davis, J. (2016). Improving university principal preparation programs: Five themes form the field. Retrieved from http://www.wallacefoundation.org/kno wledge-center/Documents/ImprovingUniversity-Principal-Preparation Programs.pdf

Davis, S. H., \& Darling-Hammond, L. (2012). Innovative principal preparation programs: What works and how we know. Planning and Changing, 43, 22-45. 
Dickey, G., Kline, J., \& Lindsteadt, G. (2016). The role of educators in preparing the confident graduate student.

InSight: A Journal of Scholarly Teaching, 11, 59-72.

Dodson, R. L. (2015). What makes them best? An analysis of the relationship between state and education quality and principal preparation practices. International Journal of Education Policy and Leadership, 10, 1-21. https://doi.org/10.22230/ijepl.2015v10n7 a634

Draeger, J. (2013). Why bother with the scholarship of teaching and learning? InSight, 8, 12-19.

Education Week (2016). Quality counts 2017: State report cards map. Retrieved from

https://www.edweek.org/ew/qc/2017/20

17-state-education-grades-map.html

Ferguson, J., \& Wilson, J. C. (2011). The co-teaching professorship: Power and expertise in the co-taught higher education classroom. Scholar-Practitioner Quarterly, 5, 52-68.

Fry, B., Bottoms, G., \& O’Neill, K. (2005). The principal internship: How can we get it right? Retrieved from

http://www.wallacefoundation.org/kno wledge-center/Documents/PrincipalInternship-Get-it-Right.pdf

Gurley, D. K., Anast-May, L., \& Lee, H. T. (2015). Developing instructional leaders through assistant principals'

academy: A partnership for success. Education and Urban Society, 47, 207-241. doi:10.1177/0013124513495272
Henley, E. M., \& Cook, S. E. (2018). Lessons from designing a co-taught interdisciplinary course. Impact: The Journal of the Center for Interdisciplinary Teaching E Learning, 7, 22-27.

Loewenberg, A. (2016). Why elementary school principals matter. Washington, DC: New America Foundation.

Lusk, M., Sayman, D., Zolkoski, S., Carrero, K., \& Chui, C. (2016). Playing well with others: Co-teaching in higher education. The Journal of the Effective Schools Project, 23, 52-61.

Mendels, P. (2016). Improving university principal preparation programs: Five themes from the field. New York, NY:

Wallace Foundation.

Merriam, S. B. (1998). Case study research in education: A qualitative approach. San Francisco, CA: Jossey-Bass.

Morelock, J. R., Lester, M. M., Klopfer, M. D., Jardon, A. M., Mullins, R. D., Nicholas, E. L., \& Alfaydi, A. S. (2017). Power, perceptions, and relationships: A model of co-teaching in higher education. College Teaching, 65, 182-191. doi: 10.1080/87567555.2017.1336610

National Policy Board for Educational Administration (2015). Professional standards for educational leaders 2015

Reston, VA.

New York City Leadership Academy (2015). Taking charge of principal preparation: A guide to NYC leadership academy's aspiring Principals program. Retrieved from http://www.wallacefoundation.org/kno wledgecenter/Documents/Taking-Charge-ofPrincipal-Preparation.pdf 
Russell, J. L., \& Sabina, L. L. (2014). Planning for principal succession: A conceptual framework for research and practice. Journal of School Leadership, 24, 599-639.

Southern Regional Education Board (2002). Universities in the lead: redesigning leadership preparation for student

achievement. Retrieved from http://www.wallacefoundation.org/kno wledge-center/Documents/Redesigning Leadership-Preparation-for-StudentAchievement.pdf

Stake, R. E. (2010). Qualitative research: Studying how things work. New York, NY: The Guilford Press.

Stone-Johnson, C. (2012). Not cut out to be an administrator: Generations, change, and the career transition from teacher to principal. Education and Urban Society, 46, 606-625.

Syed, S. (2015). Building principal pipelines: A strategy to strengthen education leadership. New York, NY: The Wallace Foundation.
Thomas, C. N., \& Kearney, K. (2010). Effective principal support: What will it take? Leadership, 40, 8-11.

Tillman, S., Arnold, C., \& Bartlett, R. (2010, August). Co-teaching in parallel: Positive impacts in advancing design students and faculty. Paper presented at the IDSA Education Symposium, Portland, OR.

Treacy, A. C., Casillas, N., \& Wiest, L. R. (2013). Exploring the importance of an introductory doctoral course. The Researcher, 25, 6-20.

Tsai, P. S., \& Wang, N. M. (2017). Biomedicine English curriculum design: Co-teaching between a biomedical profession and an English instructor. Retrieved from http://ir.lib.cyut.edu.tw:8080/bitstream/ 310901800/33733/1/13.pdf

Waters, J. T., Marzano, R. J., \& McNulty, R. A. (2003). Balanced leadership: What 30 years of research tells us about the effect of leadership on student achievement. Aurora, CO: McREL. 
Jafeth Sanchez, PhD, is an assistant professor at the University of Nevada, Reno. She focuses on developing highly effective school leaders in K12 education, having recently worked to redesign the principal preparation program, Nevada Leads. Her research agenda is on educational leadership practices, organizational change efforts, gender and ethnic equity, and areas related to students' high school and postsecondary outcomes. Her passion for educational improvement and access to higher education are embedded in all aspects of her work in teaching, research, and service.

Kelly Humphreys, PhD, has been an educator for 25 years and served communities in urban and suburban settings in multiple states, and in PreK through $12^{\text {th }}$ grade levels. She presently serves a public school district, where she has been a school psychologist, district level administrator, and elementary school principal. With more than 12 years' experience in several different administrative roles, she continues to bring passion to developing "the whole child" in her leadership. Collaboration, influencing educators' capacity to be their best, and partnering with families and the community to achieve positive outcomes remain her top goals for students.

Kevin Carroll, MEd, is the principal of Sparks High School in Nevada. He has been in education for 26 years as a teacher, assistant principal, and, for the past seven years, a middle school and high school principal. He is now a co-instructor at the University of Nevada, Reno and mentors three interns who are a part of the Nevada Leads master's program. He is also a mentor for new principals in the local school district and participates in the Executive Leadership Academy through the Public Education Foundation of Nevada.

"Rather than thinking in terms of the traditional dichotomy of research and teaching, a separation that often paralyzed higher education in the twentieth century, we can begin to think of ourselves as a learning university concerned with the learning of both faculty (research) and students (teaching) and the ways in which the learning of one can benefit the other."

$\sim$ Ken Bain, What the Best College Teachers Do 